\title{
Development and validation of an automated liquid-liquid extraction GC/MS method for the determination of THC, 11-OH-THC, and free THC-carboxylic acid (THC-COOH) from blood serum
}

\author{
Kirsten Purschke ${ }^{1} \cdot$ Sonja Heinl $^{2}$ - Oliver Lerch ${ }^{3} \cdot$ Freidoon Erdmann $^{2} \cdot$ Florian $_{\text {Veit }}{ }^{2}$
}

Received: 11 January 2016/Revised: 21 March 2016 / Accepted: 1 April 2016/Published online: 26 April 2016

(C) The Author(s) 2016. This article is published with open access at Springerlink.com

\begin{abstract}
The analysis of $\Delta^{9}$-tetrahydrocannabinol (THC) and its metabolites 11-hydroxy- $\Delta^{9}$-tetrahydrocannabinol (11-OH-THC), and 11-nor-9-carboxy- $\Delta^{9}$-tetrahydrocannabinol (THC-COOH) from blood serum is a routine task in forensic toxicology laboratories. For examination of consumption habits, the concentration of the phase I metabolite THC$\mathrm{COOH}$ is used. Recommendations for interpretation of analysis values in medical-psychological assessments (regranting of driver's licenses, Germany) include threshold values for the free, unconjugated THC-COOH. Using a fully automated two-step liquid-liquid extraction, THC, 11-OH-THC, and free, unconjugated THC-COOH were extracted from blood serum, silylated with $N$-methyl- $N$-(trimethylsilyl) trifluoroacetamide (MSTFA), and analyzed by GC/MS. The automation was carried out by an x-y-z sample robot equipped with modules for shaking, centrifugation, and solvent evaporation. This method was based on a previously developed manual sample preparation method. Validation guidelines of the Society of Toxicological and Forensic Chemistry (GTFCh) were fulfilled for both methods, at which the focus of this article is the automated one. Limits of detection and quantification for THC were 0.3 and $0.6 \mu \mathrm{g} / \mathrm{L}$, for $11-\mathrm{OH}-$ THC were 0.1 and $0.8 \mu \mathrm{g} / \mathrm{L}$, and for THC-COOH were 0.3 and $1.1 \mu \mathrm{g} / \mathrm{L}$, when extracting only $0.5 \mathrm{~mL}$ of blood serum.
\end{abstract}

Florian Veit

Florian.Veit@innere.med.uni-giessen.de

1 Bonn-Rhein-Sieg University of Applied Science, von-Liebig-Straße 20, 53359 Rheinbach, Germany

2 Department of Forensic Toxicology, University Hospital Giessen and Marburg GmbH, Institute of Legal Medicine, Frankfurter Straße 58, 35392 Giessen, Germany

3 GERSTEL GmbH \& Co. KG, Eberhard-Gerstel-Platz 1, 45473 Muelheim, Germany
Therefore, the required limit of quantification for THC of $1 \mu \mathrm{g} / \mathrm{L}$ in driving under the influence of cannabis cases in Germany (and other countries) can be reached and the method can be employed in that context. Real and external control samples were analyzed, and a round robin test was passed successfully. To date, the method is employed in the Institute of Legal Medicine in Giessen, Germany, in daily routine. Automation helps in avoiding errors during sample preparation and reduces the workload of the laboratory personnel. Due to its flexibility, the analysis system can be employed for other liquid-liquid extractions as well. To the best of our knowledge, this is the first publication on a comprehensively automated classical liquid-liquid extraction workflow in the field of forensic toxicological analysis.

Keywords Cannabinoids · Unconjugated THC-COOH • Liquid-liquid extraction (LLE) $\cdot$ Automation $\cdot$ GC/MS

\section{Introduction}

In the last decades, cannabis was, besides alcohol and tobacco, the most commonly used and also the most controversial discussed (illicit) drug in Germany. Also, driving under the influence of cannabis is becoming a more and more serious issue. Driving license regulations (German law: $\S 14 \mathrm{FeV}$ Annex 4 no. 9.2) imply that the aptitude for driving a vehicle is not given if regular cannabis consumption can be proven. In such cases, the driving license can be denuded.

In forensic laboratories, evaluation of cannabis consumption is done by urine, blood, hair, or saliva analysis. In hair and urine, cannabinoids can be detected for a longer period of time than in blood. Therefore, in Germany, these matrices are used as part of an abstinence control in medical-psychological assessments [1] to re-obtain the driver's license. By determining 
$\Delta^{9}$-tetrahydrocannabinol (THC) and its metabolites in blood (serum), laboratories determine the current state of intoxication.

$\Delta^{9}$-Tetrahydrocannabinol is the main psychotropic compound in cannabis which is metabolized in the body to 11hydroxy- $\Delta^{9}$-tetrahydrocannabinol (11-OH-THC), 11-nor-9carboxy- $\Delta^{9}$-tetrahydrocannabinol (THC-COOH), and 11nor-9-carboxy- $\Delta^{9}$-tetrahydrocannabinol glucuronide (THCCOOgluc). In the first phase of metabolism in which oxidation, reduction, and/or hydrolysis take place, THC is converted to the still pharmacologically active hydroxy metabolite 11-OH-THC. Afterwards, 11-OH-THC is oxidized in the liver to the psychotropically inactive metabolite THC-COOH. This is followed by the enzymatically catalyzed conjugation with glucuronic acid to form the phase II metabolite THCCOOgluc [2]. After 30-60 min, the concentration of the glucuronide exceeds that of the free carboxylic acid [3]. Glucuronidation makes the molecule more hydrophilic; thus, the excretion via urine is improved and THC-COOgluc constitutes the main metabolite in urine.

Up to a limit of $1 \mu \mathrm{g} / \mathrm{L} \mathrm{THC}$ in serum, it is considered that the driving ability is not impaired (German law: $§ 24$ a (2) StVG). Moreover, there are limits for the slowly degrading (half-life 6 days), inactive phase I metabolite THC-COOH [4]. This analyte serves to evaluate the consumption behavior of a driver. It must be ensured that only the free THC-COOH (free carboxylic acid) concentration is determined and this is not erroneously increased by coextraction and/or cleavage of the conjugated phase II metabolite THC-COOgluc [5].

Originally, gas chromatographic separation coupled to mass spectrometric detection with electron impact ionization using the single ion monitoring mode (GC/EI-SIM-MS) was employed to quantify cannabinoids in serum, plasma, or whole blood [6-10]. Moreover, GC/MS with positive chemical ionization has been employed [11]. In order to gain selectivity, GC/MS/MS methods have been developed, using electron impact [12] or negative chemical ionization [13]. Twodimensional GC/MS has been used as an alternative to improve selectivity $[14,15]$. Analyte derivatization is predominantly carried out with silylation reagents $[9,11,12,14,15]$ and sometimes with fluorinated compounds $[6,13]$ or methylation reagents $[7,8,10]$. In recent years, more and more liquid chromatography tandem mass spectrometry (LC/MS/ MS) methods were described in the literature [16-23]. For sample preparation, both solid-phase extraction (SPE) [7-12, 14-16, 19-21] and liquid-liquid extraction (LLE) techniques $[6,13,17,18,22]$ have been applied. In routine forensic analysis, oftentimes, liquid-liquid extraction with $n$-hexane/ethyl acetate $(9 / 1, v / v)$ is employed $[6,18,22]$. Under certain conditions, THC-COOgluc may be coextracted and partly cleaved during the derivatization step forming the THC-COOH derivative and thus leading to erroneously elevated $\mathrm{THC}-\mathrm{COOH}$ analysis values [20, 24].
Manual sample preparation normally comprises numerous steps representing a significant workload for laboratory staff with exposure to potentially toxic solvents and reagents, and it means that errors are more likely to occur. Therefore, complete automation of the analysis is preferable. Fully automated and partly automated sample preparation, mainly for SPE, is applied in some forensic laboratories. Benchtop systems using standard SPE cartridges mimic the manual SPE workflow [9, 10]. Complete automation of sample preparation and analysis is possible with online SPE systems where the SPE cartridge is integrated into an LC flow path and the cartridge is automatically exchangeable $[19,25]$ or not $[16,20]$. Complete automation of SPE, evaporation, derivatization, and injection into a chromatographic system are possible as well [26]. Automation of liquid-liquid extraction is more difficult. It can be realized in the form of, e.g., single-drop microextraction [27] or in 96-well format micro-tubes [28].

The aim of this study was the development of a comprehensively automated analysis method for the determination of THC, THC-OH, and free THC-COOH in blood serum basing on a previously developed manual method.

\section{Materials and methods}

\section{Solvents, reagents, and standards}

All analytes and deuterated analogs were certified standards. $(-)-\Delta^{9}$-THC (1 g/L in methanol), (-)- $\Delta^{9}-$ THC$^{-} \mathrm{d}_{3},( \pm)-11-$ hydroxy- $\Delta^{9}$-THC, $( \pm)$-11-hydroxy- $\Delta^{9}-\mathrm{THC}_{3},( \pm)$-11-nor9-carboxy- $\Delta^{9}$-THC, $( \pm)$-11-nor-9-carboxy- $\Delta^{9}-$ THC- $_{3},(+)$ 11-nor-9-carboxy- $\Delta^{9}$-THC-glucuronide, and $( \pm)$-11-nor-9carboxy- $\Delta^{9}-\mathrm{THC}-\mathrm{d}_{3}$-glucuronide (each $0.1 \mathrm{~g} / \mathrm{L}$ in methanol) were purchased from Cerilliant (Round Rock, USA). Blood serum samples were taken from real forensic cases of the Institute of Legal Medicine (Giessen, Germany). Internal quality control (QC) samples consisted of drug-negative serum given by voluntary donors from the institute spiked with THC, 11-OH-THC, and THC-COOH. Two QCs were prepared, the first one containing $1 \mu \mathrm{g} / \mathrm{L}$ THC and 11-THC-OH and $10 \mu \mathrm{g} / \mathrm{L}$ THC-COOH and the second one containing $30 \mu \mathrm{g} / \mathrm{L} \mathrm{THC}$ and $11-\mathrm{THC}-\mathrm{OH}$, and $300 \mu \mathrm{g} / \mathrm{L}$ THC-COOH. External quality control samples were certified reference materials (ACQ Science GmbH, Rottenburg-Hailfingen, Germany). An internal standard solution was prepared at $5 \mu \mathrm{g} / \mathrm{L} \mathrm{THC}-\mathrm{d}_{3}$ and $11-\mathrm{OH}-\mathrm{THC}-\mathrm{d}_{3}$ as well as $50 \mu \mathrm{g} / \mathrm{L}$ THC-COOH- $\mathrm{d}_{3}$ in methanol. Calibration solutions were prepared either by diluting the certified standards in methanol or by spiking drug-negative serum.

All solvents were of analytical grade and purchased from VWR (Darmstadt, Germany). For liquid-liquid extraction, a mixture of $n$-hexane and ethyl acetate $(9 / 1, v / v)$ was prepared. $N$-Methyl- $N$-(trimethylsilyl) trifluoroacetamide (MSTFA) for 
silylation was from Macherey-Nagel (Dueren, Germany). Derivatization was carried out either with pure MSTFA in the manual workflow or with a mixture of MSTFA/ethyl acetate $(3 / 2, v / v)$ in the automated workflow.

\section{Instrumentation-manual liquid-liquid extraction workflow}

For manual extraction, a Vortex-Genie 2 (Scientific Industries, New York, USA) was employed. The extraction tubes were put into an EBA 200 centrifuge (Hettich, Tuttlingen, Germany) for phase separation. After withdrawal of the organic phase, it was evaporated in a heating block (Barkey, Leopoldshöhe, Germany) with ten nitrogen-streamed vial positions (Linde, Pullach, Germany). Derivatization was carried out in a laboratory oven (Memmert, Schwabach, Germany).

The extracts were analyzed with an $6890 \mathrm{GC} / 5973 \mathrm{~N}$ MSD (Agilent Technologies, Waldbronn, Germany). A 7683 autosampler was applied for injection into a hot split/splitless inlet (Agilent Technologies). Analytes were separated on an Optima 5 HT $(30 \mathrm{~m} \times 0.25 \mathrm{~mm}, 0.25 \mu \mathrm{m}$ film thickness, Macherey-Nagel) column.

\section{Instrumentation — automated liquid-liquid extraction workflow}

Comprehensive automation of sample preparation was based on a MultiPurpose Sampler MPS (GERSTEL, Muelheim, Germany; see Fig. 1) which is a flexible platform with numerous available modules. It carried two syringes, a $1 \mathrm{~mL}$ for sample preparation steps and a $10 \mu \mathrm{L}$ for sample injection into a 7890A GC/5975C MSD (Agilent Technologies) equipped with a DB-5-MS $(30 \mathrm{~m} \times 0.25 \mathrm{~mm}, 0.25 \mu \mathrm{m}$ film thickness, Agilent Technologies) column. The MPS was equipped with a centrifuge (CF 200), a module for evaporation of solvents under controlled vacuum and temperature (Multi Position Evaporation Station, ${ }^{m}$ VAP), a ${ }^{\text {quick }}$ Mix for sample extraction, and a Solvent Filling Station (SFS 2, all GERSTEL) for solvent supply. All sample preparation steps were performed in septum-sealed vials with magnetic screw caps enabling transport by the MPS. The system was controlled via Maestro software (version 1.4.33.3, GERSTEL) which was integrated into the ChemStation chromatography data system (version E.02.02 SP1, Agilent Technologies). With this software configuration, all sample preparation steps could be combined freely and were included into the GC/MS analysis method.

\section{Analysis methods-manual liquid-liquid extraction workflow}

One milliliter of blood serum was mixed with $50 \mu \mathrm{L}$ of the deuterated internal standard solution. Liquid-liquid extraction was carried out with $5 \mathrm{~mL} n$-hexane/ethyl acetate $(9 / 1, v / v)$ for 1 min on a vortex shaker. After centrifugation $(\mathrm{RCF}=2500 \times g)$, the organic phase was withdrawn; the remaining aqueous sample was acidified with $100 \mu \mathrm{L}$ of $1 \mathrm{M}$ $\mathrm{HCl}$ (resulting $\mathrm{pH} 4-5$ ), extracted, and centrifuged again to obtain a second extract. The combined organic phases were evaporated to dryness under nitrogen at $48{ }^{\circ} \mathrm{C}$. For derivatization, the dry sample was silylated with $50 \mu \mathrm{L}$ MSTFA in an oven at $80{ }^{\circ} \mathrm{C}$ for $30 \mathrm{~min}$. Finally, $2 \mu \mathrm{L}$ of the sample was injected into the split/splitless inlet of the GC/MS at $280{ }^{\circ} \mathrm{C}$. Separation was achieved with a constant helium flow of
Fig. 1 GC/MS with MPS Dual Head at the Institute of Legal Medicine, Giessen, Germany. Modules from left to right:

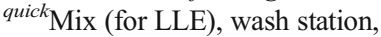
tray 1 (vials for extracts), solvent reservoir, ${ }^{m}$ VAP (for extract evaporation), Solvent Filling Station (solvent supply), cooled tray 2 (vials for serum samples), and centrifuge (for phase separation)

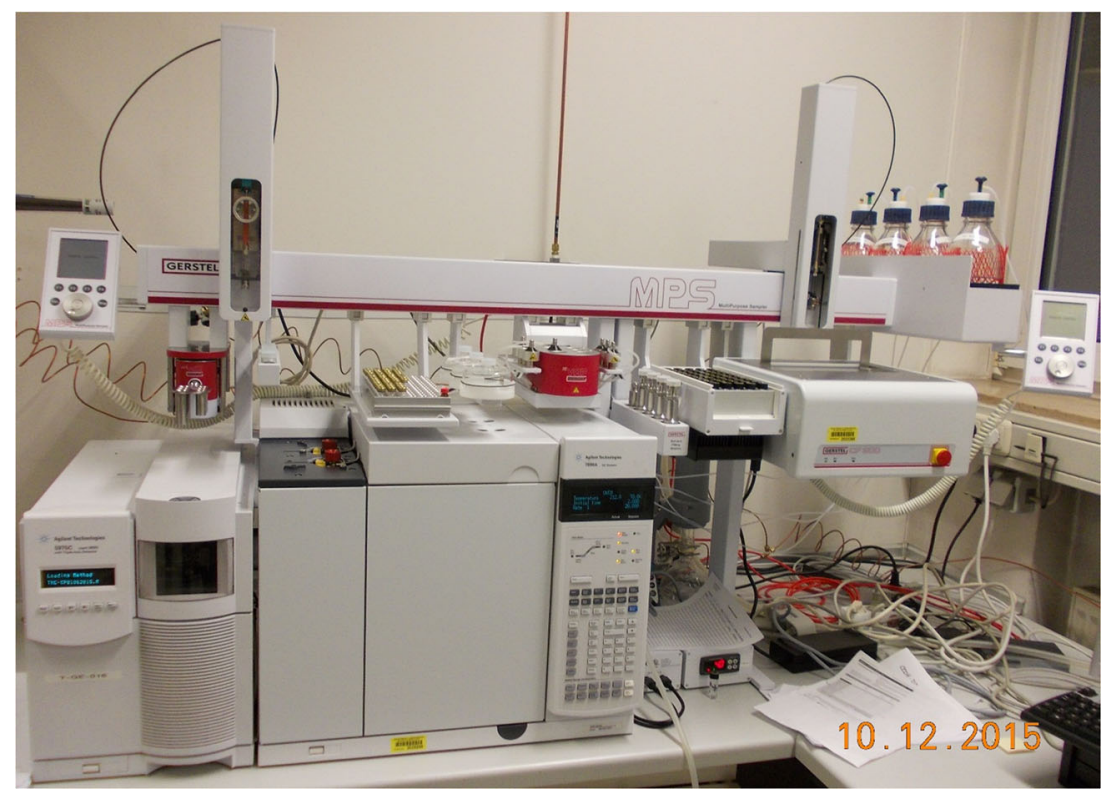


Table 1 Target and qualifier ions for analytes and deuterated internal standards

\begin{tabular}{llll}
\hline & Target $(\mathrm{m} / \mathrm{z})$ & Qualifier 1 $(\mathrm{m} / \mathrm{z})$ & Qualifier 2 $(\mathrm{m} / \mathrm{z})$ \\
\hline THC & 386 & 371 & 303 \\
THC-d $_{3}$ & 389 & 374 & 306 \\
$11-\mathrm{OH}-\mathrm{THC}$ & 371 & 474 & 459 \\
$11-\mathrm{OH}-\mathrm{THC}-\mathrm{d}_{3}$ & 374 & 477 & 462 \\
THC-COOH & 371 & 473 & 488 \\
THC-COOH-d & 374 & 476 & 491 \\
\hline
\end{tabular}

$1.3 \mathrm{~mL} / \mathrm{min}$ and the following temperature program: $70^{\circ} \mathrm{C}$ for $2 \mathrm{~min}$, rate $20{ }^{\circ} \mathrm{C} / \mathrm{min}$ to $250{ }^{\circ} \mathrm{C}$ for $4 \mathrm{~min}$, rate $20{ }^{\circ} \mathrm{C} / \mathrm{min}$ to $300{ }^{\circ} \mathrm{C}$ for $17 \mathrm{~min}$. Mass spectrometric detection was done in single ion monitoring (SIM) mode (see Table 1).

\section{Analysis methods-automated liquid-liquid extraction workflow}

For automation, $0.5 \mathrm{~mL}$ of blood serum was manually mixed with $25 \mu \mathrm{L}$ of the deuterated internal standard solution in a 4-mL vial. All further steps were carried out fully automated by the MPS. The sample was extracted with $1.5 \mathrm{~mL} n$-hexane/ethyl acetate $(9 / 1, v / v)$ for $3 \mathrm{~min}$ in the ${ }^{\text {quick }} \mathrm{Mix}$ and centrifuged for phase separation at $\mathrm{RCF}=2000 \times \mathrm{g}$ for $7 \mathrm{~min}$. The supernatant was taken into another vial and evaporated to dryness under controlled vacuum (1 min at $70 \mathrm{kPa}, 3.5 \mathrm{~min}$ at $4 \mathrm{kPa}$ ) and temperature $\left(65^{\circ} \mathrm{C}\right)$ and shaking $(3.1 \mathrm{~Hz})$ in the evaporation station while the residue was acidified with $50 \mu \mathrm{L}$ of $1 \mathrm{M} \mathrm{HCl}$ (resulting $\mathrm{pH} 4-5$ ). After acidic extraction, again with $1.5 \mathrm{~mL} n$-hexane/ethyl acetate $(9 / 1, v / v)$, the organic phase was separated, transferred to the same extract vial, and evaporated again until dryness was reached. A mixture of $50 \mu \mathrm{L}$ MSTFA/ethyl acetate $(3 / 2, v / v)$ was added to the dry residue, the vial was shortly shaken, and $2 \mu \mathrm{L}$ was injected into the hot split/splitless inlet (derivatization at $280{ }^{\circ} \mathrm{C}$ ) of the GC/MS. For practical reasons, the temperature program was changed compared to the manual method, since there was a second GC column for a different application installed in the same GC oven which could not withstand temperatures higher than $260{ }^{\circ} \mathrm{C}$. Separation was performed with a constant helium flow of $1.6 \mathrm{~mL} / \mathrm{min}$ and the following temperature program: $70{ }^{\circ} \mathrm{C}$ for $2 \mathrm{~min}$, rate $20^{\circ} \mathrm{C} / \mathrm{min}$ to $240{ }^{\circ} \mathrm{C}$ for $5 \mathrm{~min}$, rate $20{ }^{\circ} \mathrm{C} / \mathrm{min}$ to $250{ }^{\circ} \mathrm{C}$ for $6 \mathrm{~min}$, rate $20^{\circ} \mathrm{C} / \mathrm{min}$ to $260{ }^{\circ} \mathrm{C}$ for $5 \mathrm{~min}$. Mass spectrometric detection was done in single ion monitoring (SIM) mode (Table 1).

For calibration, both methanolic solutions and spiked serum samples were employed. Methanolic calibration solutions and the methanolic control samples were handled analogously to the extracts. Calibration with solvent standards is often used in forensic toxicology and is accepted by the Society of Toxicological and Forensic Chemistry (GTFCh) if equivalence with matrix calibration can be proven. The manual and automated analysis methods were validated according to GTFCh guidelines with the help of the software Valistat (version 1.0) from Arvecon (Walldorf, Germany).

Analysis sequences comprised 20 real cases and four control samples (negative, low concentration, high concentration, and external). According to GTFCh recommendations, a blank injection of pure derivatization reagent was done before every real sample.

\section{Results and discussion}

\section{Method development}

A dual-stage liquid-liquid extraction method for the determination of THC, 11-OH-THC, and free THC-COOH in blood serum was developed. Considering the different $\mathrm{p} K a$ values of the analytes, the first extraction was carried out at the native $\mathrm{pH}$ of the blood serum (around $\mathrm{pH} 7$ ). At this $\mathrm{pH}$, mainly THC and 11-OH-THC which are non-charged were extracted into
Table 2 Comparison of THC$\mathrm{COOH} / \mathrm{THC}-\mathrm{COOH}-\mathrm{d}_{3}$ ratios for blank serum spiked at $50 \mu \mathrm{g} / \mathrm{L}$ with THC-COOH and THC$\mathrm{COOH}-\mathrm{d}_{3}$ only and blank serum additionally spiked at $50 \mu \mathrm{g} / \mathrm{L}$ with THC-COOgluc. Analysis results for $\mathrm{THC}-\mathrm{COOH}$ are not biased by THC-COOgluc addition

\begin{tabular}{|c|c|c|c|c|c|c|}
\hline \multicolumn{3}{|c|}{$\begin{array}{l}\text { Blank serum spiked with THC-COOH } \\
\text { and THC-COOH- } \mathrm{d}_{3}\end{array}$} & \multicolumn{3}{|c|}{$\begin{array}{l}\text { Blank serum additionally spiked with } \\
\text { THC-COOgluc }\end{array}$} & \multirow[t]{2}{*}{$\begin{array}{l}\text { Difference } \\
\text { of ratios }\end{array}$} \\
\hline $\begin{array}{l}\text { Response } \\
\text { THC-COOH }\end{array}$ & $\begin{array}{l}\text { Response } \\
\text { THC-COOH-d }\end{array}$ & Ratio & $\begin{array}{l}\text { Response } \\
\text { THC-COOH }\end{array}$ & $\begin{array}{l}\text { Response } \\
\text { THC-COOH-d }\end{array}$ & Ratio & \\
\hline 7348 & 6907 & 1.064 & 7395 & 6564 & 1.127 & +0.063 \\
\hline 7896 & 6884 & 1.147 & 8856 & 7833 & 1.131 & -0.016 \\
\hline 6854 & 6320 & 1.085 & 7606 & 6683 & 1.138 & +0.054 \\
\hline 7967 & 7176 & 1.110 & 6503 & 5468 & 1.189 & +0.079 \\
\hline \multirow[t]{2}{*}{7409} & 6179 & 1.199 & 7935 & 7192 & 1.103 & -0.096 \\
\hline & Average & 1.121 & & & 1.138 & +0.017 \\
\hline
\end{tabular}


Fig. 2 Chromatograms of serum samples spiked with $4 \mu \mathrm{g} / \mathrm{L}$ THC and THC-OH and $40 \mu \mathrm{g} / \mathrm{L}$ THC$\mathrm{COOH}$ after extraction and derivatization with MSTFA in an oven for $30 \mathrm{~min}$ at $80^{\circ} \mathrm{C}$ (a) and derivatization with MSTFA/ethyl acetate $(3 / 2, v / v)$ in the GC inlet at $280{ }^{\circ} \mathrm{C}(\mathbf{b})$

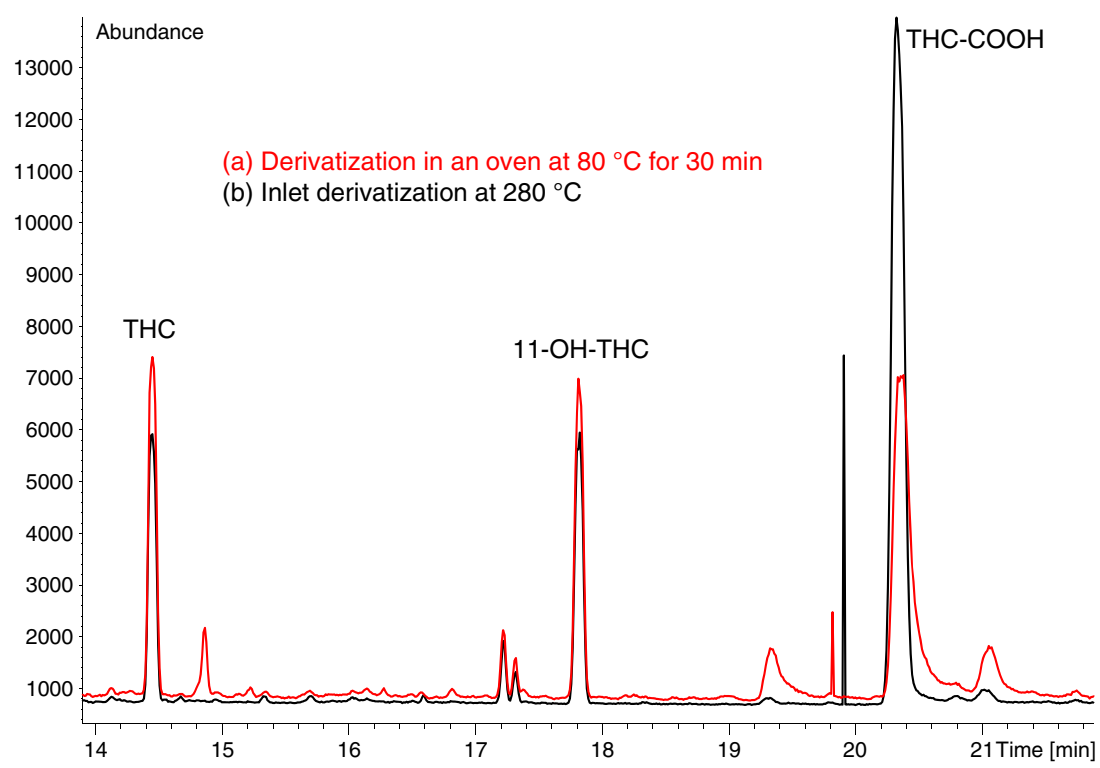

the organic phase. In the second extraction step, after acidification of the residual sample to $\mathrm{pH} 4-5$, free THC-COOH was extracted and separated from THC-COOgluc. At this $\mathrm{pH}$, THC-COOgluc (pKa 3.2 [29]) predominantly (about $90 \%$ ) is present deprotonated (anionic) and thus cannot pass into the organic phase. Free THC-COOH (pKa 4.2 [29]), however, is protonated and non-charged (about $50 \%$ ) and can be extracted into the organic phase. Maintaining the $\mathrm{pH}$ between 4 and 5 is crucial for the second extraction step. Major deviations can lead to glucuronide cleavage [3] or coextraction of THCCOOgluc which forms silylated THC-COOH during the derivatization step. Eventually, both effects result in erroneously elevated THC-COOH analysis values [20, 24].

For confirming that the developed analysis method does not result in elevated THC-COOH values, the following experiment was conducted: 12 samples of blank blood serum were spiked with equal amounts of THC$\mathrm{COOH}$ and the internal standard THC-COOH-d $\mathrm{d}_{3}$. Six of these samples were additionally spiked with THCCOOgluc. The peak area ratio THC-COOH/THC-
$\mathrm{COOH}-\mathrm{d}_{3}$ was calculated for all analyses. On average, the samples additionally spiked with THC-COOgluc showed a $1.5 \%$ higher ratio proving that only negligible amounts of THC-COOH were formed from THCCOOgluc by the sample preparation steps (see Table 2). In that respect, recommendations for interpretation of analysis values in medical-psychological assessments requiring the analysis of free $\mathrm{THC}-\mathrm{COOH}$ only without interferences by THC-COOgluc were fulfilled.

The developed two-step liquid-liquid extraction was successfully and completely automated using a MultiPurpose Sampler equipped with different modules (e.g., shaker, centrifuge, evaporator). Some analysis parameters were improved or needed to be adapted for automation.

The sample volume could be reduced from 1 to $0.5 \mathrm{~mL}$ serum. Also, the volume of the extraction solvent for each extraction step was reduced from 5 to $1.5 \mathrm{~mL} n$-hexane/ ethyl acetate $(9 / 1, v / v)$. This enabled the use of $4-\mathrm{mL}$ vials for extraction, extending the sample capacity to 50 samples per sequence.
Table 3 Excerpt of validation data of the automated analysis method according to GTFCh guidelines

\begin{tabular}{llllll}
\hline Analyte & $\begin{array}{l}\text { Concentration } \\
{[\mu \mathrm{g} / \mathrm{L}]}\end{array}$ & $\begin{array}{l}\text { Repeatability: } \\
\mathrm{RSD}_{\mathrm{r}}[\%]\end{array}$ & $\begin{array}{l}\text { Time-different } \\
\text { intermediate } \\
\text { precision: } \mathrm{RSD}_{(\mathrm{T})} \\
{[\%]}\end{array}$ & $\begin{array}{l}\text { Accuracy: } \\
\text { bias [\%] }\end{array}$ & $\begin{array}{l}\text { Extraction } \\
\text { efficiency } \\
{[\%]}\end{array}$ \\
\hline THC & 1 & 7.8 & 6.1 & 2.1 & 109 \\
& 30 & 2.1 & 8.5 & 0.7 & 103 \\
$11-\mathrm{OH}-\mathrm{THC}$ & 1 & 8.3 & 8.1 & 4.1 & 120 \\
& 30 & 1.8 & 8.7 & -0.3 & 103 \\
THC-COOH & 10 & 2.4 & 6.3 & 3.0 & 121 \\
& 300 & 0.9 & 12 & 0.9 & 104 \\
\hline
\end{tabular}


Table 4 Limits of detection (LOD) and limits of quantification (LOQ) for the automated method

\begin{tabular}{llll}
\hline & THC $[\mu \mathrm{g} / \mathrm{L}]$ & $11-\mathrm{OH}-\mathrm{THC}[\mu \mathrm{g} / \mathrm{L}]$ & THC-COOH $[\mu \mathrm{g} / \mathrm{L}]$ \\
\hline LOD & 0.3 & 0.1 & 0.3 \\
LOQ & 0.6 & 0.8 & 1.1 \\
\hline
\end{tabular}

Centrifugation time and needle penetration depth for the extract withdrawal step needed to be optimized carefully since it is crucial to prevent contamination of the final extract by residual serum. Also, optimal evaporation parameters had to be found out ensuring on the one hand that the extract is completely evaporated before derivatization and on the other hand that the analytes are not exposed to heat in the ${ }^{m}$ VAP longer than necessary.

Analyte derivatization can be done during injection into the hot split/splitless inlet with a mixture of MSTFA/ethyl acetate $(3 / 2, v / v)$ instead of pure MSTFA. In comparison to the 30 min derivatization step in an oven, this saves time and increases throughput while analytical performance is maintained. Chromatograms of the inlet derivatization showed less and smaller background peaks than chromatograms received with 30 min derivatization in an oven (see Fig. 2). The reduction of MSTFA volume percentage enhances the lifetime of the analytical column and the autosampler syringe according to former experiences with silylation reagents in our laboratory.

\section{Method validation}

Requirements of the validation according to GTFCh guidelines [30] have been met at each point for both the manual and automated methods. Only validation data for the automated method are discussed here.
Selectivity and specificity were checked by analyzing six different serum samples spiked with opiates and benzodiazepines as they could be present in real samples as well. No interferences from the spiked drugs or the matrix were recorded at the retention time of analytes and internal standards of interest.

Linearity of calibration was proven up to $35 \mu \mathrm{g} / \mathrm{L}$ for THC and 11-OH-THC and up to $350 \mu \mathrm{g} / \mathrm{L}$ for THC$\mathrm{COOH}$ respectively. A calibration with standards in methanol was equivalent to a matrix calibration and therefore was employed for analyzing real samples. Precision, accuracy, and extraction efficiency data can be found in Table 3. All precision and accuracy values were below the acceptable value of $15 \%$. The average extraction efficiency was $110 \%$ ranging from 103 to $121 \%$. Limits of quantification (LOQ) and detection (LOD) for the respective compounds are listed in Table 4. Most importantly, the limit of quantification for $\mathrm{THC}$ was far below $1 \mu \mathrm{g} / \mathrm{L}$, being an important limit in driving under the influence of cannabis cases in Germany and other countries. No carry-over was detected for any compound when analyzing a blank serum sample after a serum sample spiked at the highest calibration level $(35 \mu \mathrm{g} / \mathrm{L}$ for THC and 11-OH-THC and $350 \mu \mathrm{g} / \mathrm{L}$ for THC-COOH). Freeze/thaw stability was confirmed by three freezing and thawing cycles with spiked QC samples of low $(1.5 \mu \mathrm{g} / \mathrm{L}$ for THC and 11$\mathrm{OH}-\mathrm{THC}$ and $15 \mu \mathrm{g} / \mathrm{L}$ for THC-COOH) and high $(12.5 \mu \mathrm{g} / \mathrm{L}$ for $\mathrm{THC}$ and $11-\mathrm{OH}-\mathrm{THC}$ and $125 \mu \mathrm{g} / \mathrm{L}$ for THC-COOH) concentrations.

Furthermore, stability of the samples on the autosampler tray during an analysis sequence was evaluated. For this, a serum pool was spiked with $30 \mu \mathrm{g} / \mathrm{L} \mathrm{THC}$ and 11-OH-THC and $300 \mu \mathrm{g} / \mathrm{L}$ THC-COOH and THC-COOgluc. Aliquots of $0.5 \mathrm{~mL}$ were put into autosampler vials. The first series

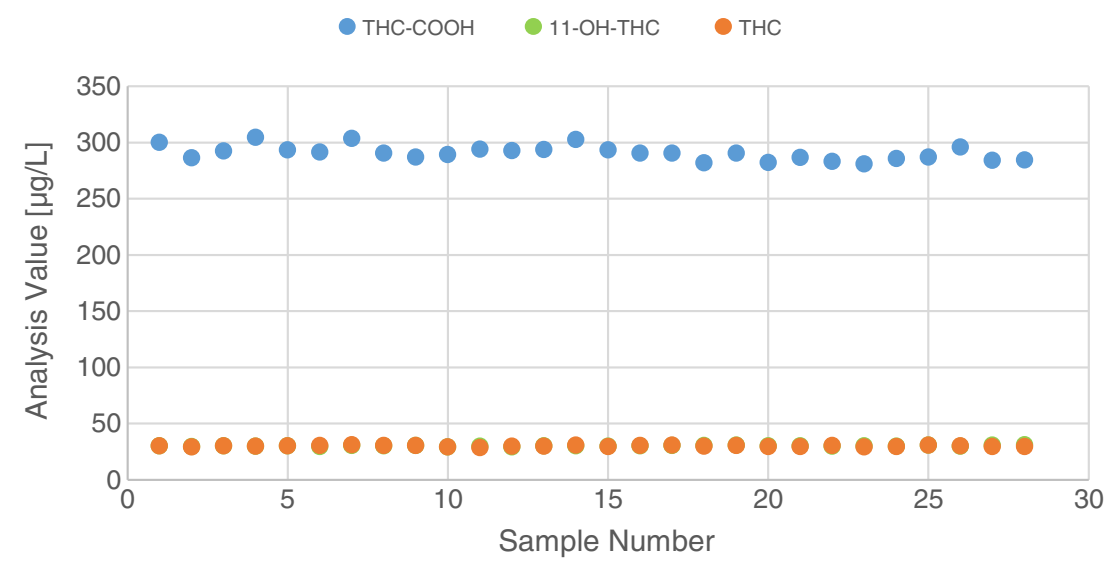

Fig. 3 Analysis values for a sequence of 28 blank serum samples spiked with $30 \mu \mathrm{g} / \mathrm{L}$ THC and 11-OH-THC and $300 \mu \mathrm{g} / \mathrm{L}$ THC-COOH and $300 \mu \mathrm{g} / \mathrm{L}$ THC-COOgluc stored on a cooled tray at $4{ }^{\circ} \mathrm{C}$. No increase of the THC-COOH value by cleavage of THC-COOgluc can be observed

during the sequence run time of more than one day. Note that data points for 11-OH-THC analysis values are overlapped by data points for THC analysis values since these analytes were spiked at the same concentration 
of samples was processed immediately; the second series was stored overnight on the autosampler tray at room temperature. Average analysis values for THC and 11-OHTHC were concordant. For THC-COOH, an increase of around $10 \%$ after storage could be observed which can be explained by THC-COOgluc degradation and the formation of THC-COOH. When storing the serum samples at $4{ }^{\circ} \mathrm{C}$ on a cooled tray and running a sequence of 28 samples (runtime more than 1 day), neither an increase nor a decrease of analysis values could be observed for all analytes (see Fig. 3). Cooling of samples is essential for running analysis sequences over a long period of time.

LOQs of the developed automated method lie well within published LOQs for GC/MS(/MS) $[6,8,9,11$, $13]$ and LC/MS/MS [16-18, 20, 21] methods. In the literature, these were between 0.5 and $1 \mu \mathrm{g} / \mathrm{L}$ for $\mathrm{THC}$ and $11-\mathrm{OH}-\mathrm{THC}$ and between 0.8 and $4.3 \mu \mathrm{g} / \mathrm{L}$ for THCCOOH. A sophisticated 2D-GC/MS method yielded LOQs of $0.125 \mu \mathrm{g} / \mathrm{L}$ for THC and THC-COOH and $0.25 \mu \mathrm{g} / \mathrm{L}$ for $11-\mathrm{OH}-\mathrm{THC}$ respectively [14]. Extraction efficiencies and recoveries mentioned in the literature were mainly lower than in the present study which might be caused by differences in the way of sample spiking. As in our application-except for THC-COOH at $300 \mu \mathrm{g} / \mathrm{L}$-relative standard deviations (precision) in the literature were below $10 \%$. A round robin test has been passed successfully with the automated method and

Table 5 Analysis results of a successfully passed round robin test (two samples) and external control samples employing the comprehensively automated method

\begin{tabular}{llll}
\hline Analyte & $\begin{array}{l}\text { Analysis value } \\
{[\mu \mathrm{g} / \mathrm{L}]}\end{array}$ & $\begin{array}{l}\text { Target value } \\
{[\mu \mathrm{g} / \mathrm{L}]}\end{array}$ & $\begin{array}{l}\text { Acceptable range } \\
{[\mu \mathrm{g} / \mathrm{L}]}\end{array}$ \\
\hline THC & $6.7^{\mathrm{a}}$ & 6.0 & $3.9-8.1$ \\
& $3.9^{\mathrm{a}}$ & 4.4 & $2.8-5.9$ \\
& $1.1^{\mathrm{b}}$ & 1.1 & $0.6-1.6$ \\
& $8.5^{\mathrm{b}}$ & 9.5 & $6.4-12$ \\
$11-\mathrm{OH}-\mathrm{THC}$ & $14^{\mathrm{b}}$ & 20 & $14-26$ \\
& $3.1^{\mathrm{a}}$ & 2.6 & $1.6-3.7$ \\
& $2.5^{\mathrm{a}}$ & 2.6 & $1.5-3.6$ \\
& $1.1^{\mathrm{b}}$ & 1.1 & $0.6-1.5$ \\
& $4.7^{\mathrm{b}}$ & 5.0 & $3.2-6.8$ \\
& $9.8^{\mathrm{b}}$ & 9.8 & $6.6-13$ \\
THC-COOH & $75^{\mathrm{a}}$ & 71 & $54-88$ \\
& $64^{\mathrm{a}}$ & 63 & $47-78$ \\
& $8.4^{\mathrm{b}}$ & 10 & $6.9-14$ \\
& $73^{\mathrm{b}}$ & 71 & $54-88$ \\
& $141^{\mathrm{b}}$ & 136 & $107-165$ \\
\hline
\end{tabular}

\footnotetext{
${ }^{\mathrm{a}}$ Round robin test sample
}

${ }^{\mathrm{b}}$ External control sample analysis values for external control samples laid inside the acceptable concentration ranges (Table 5).

\section{Comparison of manual and automated methods}

In order to check the newly validated methods (manual and automated), 20 real samples from the Institute of Legal Medicine in Giessen and various external controls were analyzed and compared.

Considering the fact that comparative analyses of real samples were conducted on different instruments, the concentration values fit quite well especially for the most important analytes THC and THC-COOH (see Fig. 4a, c). For 11-OH-THC, the deviation of analysis values was slightly larger but acceptable (see Fig. 4b). All analysis values for 11-OH-THC fall in the lower concentration range where 11-OH-THC reveals the highest bias and lowest repeatability of all compounds for both the automated (Table 3) and manual methods (not shown). This may explain the larger deviations for 11-OH-THC in comparison to THC and THC-COOH.

After successful validation, both the automated and manual methods for the determination of THC and metabolites in serum are suitable for use in forensic toxicological analysis. It is noteworthy that postmortem samples cannot be analyzed ruggedly with the automated method because of the possible formation of a gel during the extraction step which cannot be separated by the standard centrifugation method.

\section{Conclusions}

One manual and one fully automated analysis method for THC, 11-OH-THC, and free, unconjugated THC$\mathrm{COOH}$ in blood serum were developed and successfully validated according to GTFCh guidelines. Analysis values were concordant, and both methods ensure that only the free THC-COOH concentration is determined and the analysis value is not erroneously increased by THC-COOgluc coextraction and/or cleavage. Regarding LOQs, extraction efficiencies, and precision, both developed methods correspond well to methods from the literature. The LOQ for THC of $1 \mu \mathrm{g} / \mathrm{L}$ required for driving under the influence of cannabis cases in Germany can be reached, and the method can be employed in that context.

To the best of our knowledge, this is the first publication on a comprehensively automated classical liquid-liquid extraction workflow in the field of forensic toxicological analysis. Also, the employed analysis system including shaker, centrifuge, and evaporator modules is mentioned for the first time in the literature. 
Fig. 4 Comparison of analysis results for manual and automated sample preparation of 20 real samples: a THC, b 11-OH-THC, c THC-COOH. Equations resulting from linear regression and coefficients of determination are shown. Not all samples included the analytes in concentrations above the respective limit of quantification
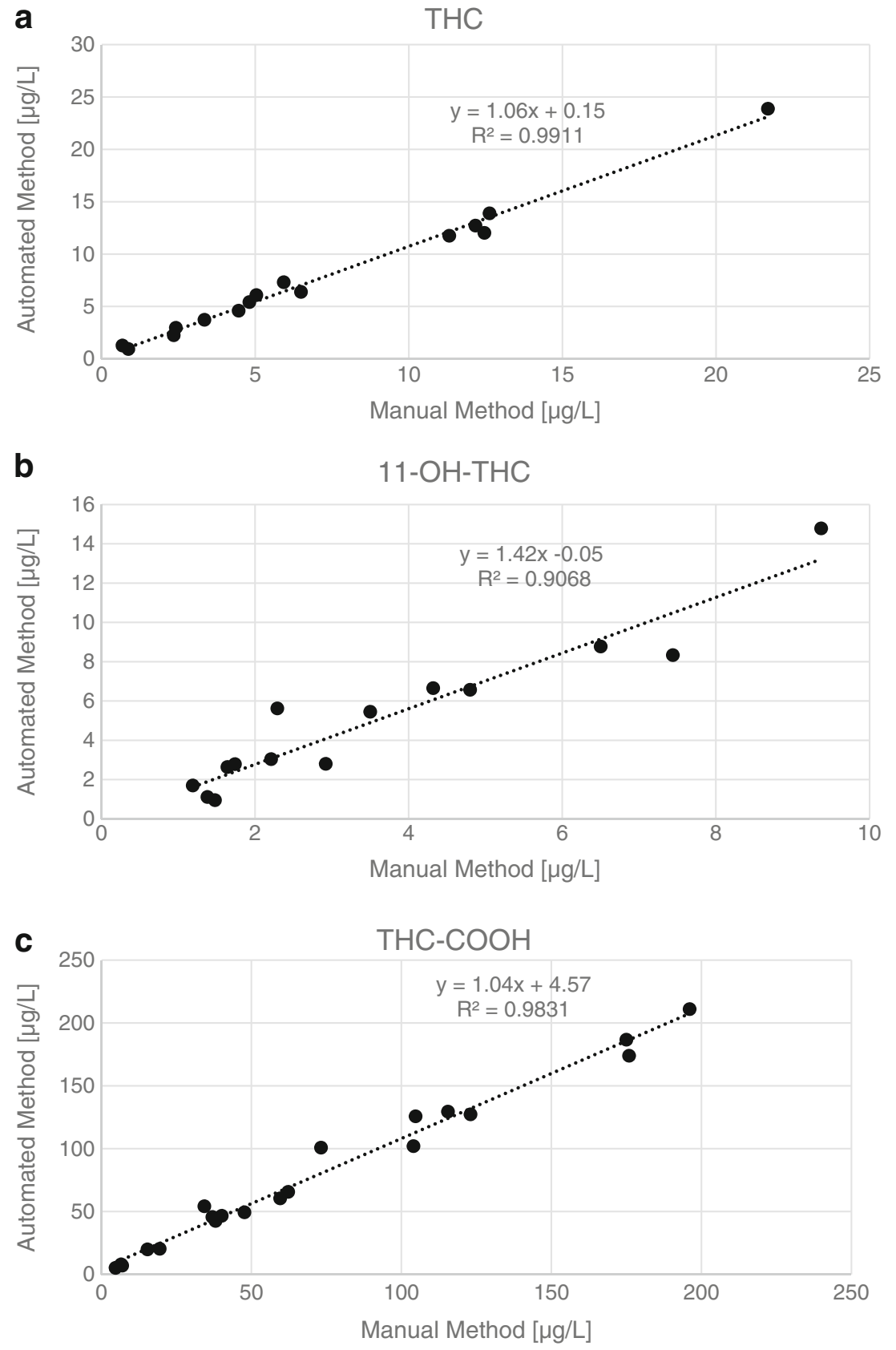

These are the main achievements and benefits:

- The automated method saves manual work and reduces the risk of human errors. This makes analysis quality projectable and more independent of the human factor.

- By overlapping sample preparation and GC/MS run, the comprehensively automated method has a throughput of 22 samples per day compared to 20 samples per day with the manual workflow. Eighty-three minutes is needed for a single analysis (including sample preparation, GC/MS analysis, and the required blank analysis), meaning that results are available 83 min after putting a single sample onto the autosampler.

- The automated method can be employed for all types of sera except postmortem samples.

- The automated system proved to be rugged and is employed in our daily routine in the institute.

- The analysis system can be used for other matrices (e.g., saliva or urine) and other liquid-liquid extraction workflows also outside the field of forensic toxicology and is therefore of general interest.

- Other liquid-liquid extraction workflows in our laboratory are actually under consideration for automation. 
Acknowledgments The authors thank their colleagues from the Institute of Legal Medicine Essen, Germany, Department of Forensic Toxicology, for sharing information on their method for THC analysis in blood serum.

Compliance with ethical standards Coauthor Oliver Lerch is an employee of GERSTEL GmbH \& Co. KG. GERSTEL instrumentation was used in this research project. The other authors declare no conflicts of interest.

Voluntary donors of blank blood samples from the Institute of Legal Medicine in Giessen gave their informed consent to use their blood in this study.

The study has been approved by the appropriate ethics committee and has been performed in accordance with the ethical standards.

Open Access This article is distributed under the terms of the Creative Commons Attribution 4.0 International License (http:// creativecommons.org/licenses/by/4.0/), which permits unrestricted use, distribution, and reproduction in any medium, provided you give appropriate credit to the original author(s) and the source, provide a link to the Creative Commons license, and indicate if changes were made.

\section{References}

1. Schubert W, Dittmann V, Brenner-Hartmann J. Urteilsbildung in der Fahrerlaubnisbegutachtung, Beurteilungskriterien. 3rd ed. Bonn: Kirschbaum; 2013. p. 245-57.

2. Grotenhermen F. Pharmacokinetics and pharmacodynamics of cannabinoids. Clin Pharmacokinet. 2003;42:327-60.

3. Skopp G, Pötsch L. Zur präanalytischen Phase chemischtoxikologischer Untersuchungen II: Stabilität forensisch relevanter Substanzen in Blut-, Plasma- oder Serumproben - eine Bestandsaufnahme. Rechtsmedizin. 2002;12:195-202.

4. Daldrup T, Käferstein H, Köhler H, Maier RD, Musshoff F. Entscheidung zwischen einmaligem/gelegentlichem und regelmäßigem Cannabiskonsum. Blutalkohol. 2000;37:39-47.

5. Musshoff F, Madea B. Review of biologic matrices (urine, blood, hair) as indicators of recent or ongoing cannabis use. Ther Drug Monit. 2006;28:155-63.

6. Chi Chu MH, Drummer OH. Determination of $\Delta^{9}$-THC in whole blood using gas chromatography-mass spectrometry. J Anal Toxicol. 2002;26:575-81.

7. Moeller MR, Doerr G, Warth S. Simultaneous quantitation of delta9-tetrahydrocannabinol (THC) and 11-nor-9-carboxy-delta-9-tetrahydrocannabinol (THC-COOH) in serum by GC/MS using deuterated internal standards and its application to a smoking study and forensic cases. J Forensic Sci. 1992;37:969-83.

8. Steinmeyer S, Bregel D, Warth S, Kraemer T, Moeller MR. Improved and validated method for the determination of $\Delta^{9}$-tetrahydrocannabinol, 11-hydroxy-THC and 11-nor-9-carboxy-THC in serum, and in human liver microsomal preparations using gas chromatography-mass spectrometry. J Chromatogr B. 2002;772: 239-48.

9. Nadulski T, Sporkert F, Schnelle M, Stadelmann AM, Roser P, Schefter T, et al. Simultaneous and sensitive analysis of THC, 11$\mathrm{OH}-\mathrm{THC}$, THC-COOH, CBD, and CBN by GC-MS in plasma after oral application of small doses of THC and cannabis extract. J Anal Toxicol. 2005;29:782-9.

10. Röhrich J, Schimmel I, Zörntlein S, Becker J, Drobnik S, Kaufmann $\mathrm{T}$, et al. Concentrations of $\Delta^{9}$-tetrahydrocannabinol and 11-nor-9-carboxytetrahydrocannabinol in blood and urine after passive exposure to cannabis smoke in a coffee shop. J Anal Toxicol. 2010;34:196-203.

11. Gustafson RA, Moolchan ET, Barnes A, Levine B, Huestis MA. Validated method for the simultaneous determination of $\Delta^{9}$-tetrahydrocannabinol (THC), 11-hydroxy-THC and 11-nor-9-carboxyTHC in human plasma using solid phase extraction and gas chromatography-mass spectrometry with positive chemical ionization. J Chromatogr B. 2003;798:145-54.

12. Weller JP, Wolf M, Szidat S. Enhanced selectivity in the determination of $\Delta 9$-tetrahydrocannabinol and two major metabolites in serum using ion-trap GC-MS-MS. J Anal Toxicol. 2000;24:35964.

13. Thomas A, Widmer C, Hopfgartner G, Staub C. Fast gas chromatography and negative-ion chemical ionization tandem mass spectrometry for forensic analysis of cannabinoids in whole blood. J Pharm Biomed. 2007;45:495-503.

14. Lowe RH, Karschner EL, Schwilke EW, Barnes AJ, Huestis MA. Simultaneous quantification of $\Delta^{9}$-tetrahydrocannabinol, 11-hydroxy- $\Delta^{9}$-tetrahydrocannabinol, and 11-nor- $\Delta^{9}$-tetrahydrocannabinol-9-carboxylic acid in human plasma using two-dimensional gas chromatography, cryofocusing, and electron impact-mass spectrometry. J Chromatogr A. 2007;1163:318-27.

15. Scurlock RD, Ohlson GB, Worthen DK. The detection of $\Delta^{9}$-tetrahydrocannabinol (THC) and 11-nor-9-carboxy- $\Delta^{9}$-tetrahydrocannabinol (THCA) in whole blood using two-dimensional gas chromatography and EI-mass spectrometry. J Anal Toxicol. 2006;30: 262-6.

16. Maralikova B, Weinmann W. Simultaneous determination of $\Delta^{9}$ tetrahydrocannabinol, 11-hydroxy- $\Delta^{9}$-tetrahydrocannabinol and 11-nor-9-carboxy- $\Delta^{9}$-tetrahydrocannabinol in human plasma by high-performance liquid chromatography/tandem mass spectrometry. J Mass Spectrom. 2004;39:526-31.

17. Laloup M, del Mar Ramirez Fernandez M, Wood M, De Boeck G, Maes V, Samyn N. Correlation of $\Delta^{9}$-tetrahydrocannabinol concentrations determined by LC-MS-MS in oral fluid and plasma from impaired drivers and evaluation of the on-site Dräger DrugTest ${ }^{\circledR}$. Forensic Sci Int. 2006;161:175-9.

18. Del Mar Ramirez Fernandez M, De Boeck G, Wood M, LopezRivadulla M, Samyn N. Simultaneous analysis of THC and its metabolites in blood using liquid chromatography-tandem mass spectrometry. J Chromatogr B. 2008;875:465-70.

19. Jagerdeo E, Schaff JE, Montgomery MA, LeBeau MA. A semiautomated solid-phase extraction liquid chromatography/tandem mass spectrometry method for the analysis of tetrahydrocannabinol and metabolites in whole blood. Rapid Commun Mass Spectrom. 2009;23:2697-705.

20. König S, Aebi B, Lanz S, Gasser M, Weinmann W. On-line SPE LC-MS/MS for the quantification of $\Delta^{9}$-tetrahydrocannabinol (THC) and its two major metabolites in human peripheral blood by liquid chromatography tandem mass spectrometry. Anal Bioanal Chem. 2011;400:9-16.

21. Schwope DM, Scheidweiler KB, Huestis MA. Direct quantification of cannabinoids and cannabinoid glucuronides in whole blood by liquid chromatography tandem mass spectrometry. Anal Bioanal Chem. 2011;401:1273-83.

22. Dubois N, Paccou AP, De Backer BG, Charlier CJ. Validation of the quantitative determination of tetrahydrocannabinol and its two major metabolites in plasma by ultra-high-performance liquid chromatography-tandem mass spectrometry according to the total error approach. J Anal Toxicol. 2012;36:25-9.

23. Toennes SW, Hanisch S, Pogoda W, Wunder C, Paulke A. Pitfall in cannabinoid analysis - detection of a previously unrecognized interfering compound in human serum. Anal Bioanal Chem. 2015;407:463-70.

24. Mauden M, Skopp G, Mattern R, Aderjan R. GC/MSdetermination of THCCOOH in serum: comparison of different 
processing methods and the influence of THCCOOHglucuronide. Blutalkohol. 2000;37:48-56.

25. Del Mar Ramirez Fernandez M, Wille SMR, Samyn N, Wood M, Lopez-Rivadulla M, De Boeck G. High-throughput analysis of amphetamines in blood and urine with online solid-phase extractionliquid chromatography-tandem mass spectrometry. J Anal Toxicol. 2009;33:578-87.

26. Lerch O, Temme O, Daldrup T. Comprehensive automation of the solid phase extraction gas chromatographic mass spectrometric analysis (SPE-GC/MS) of opioids, cocaine, and metabolites from serum and other matrices. Anal Bioanal Chem. 2014;406:4443-51.

27. He Y, Kang YJ. Single drop liquid-liquid-liquid microextraction of methamphetamine and amphetamine in urine. J Chromatogr A. 2006;1133:35-40.
28. Dotsikas Y, Kousoulos C, Tsatsou G, Loukas YL. Development of a rapid method for the determination of glimepiride in human plasma using liquid-liquid extraction based on 96-well format microtubes and liquid chromatography/tandem mass spectrometry. Rapid Commun Mass Spectrom. 2005;19:2055-61.

29. Chemicalize.org. In: Properties Viewer, Search for: "d-glucuronic acid" and "11-nor-9-carboxy-THC". 2016. http://www. chemicalize.org. Accessed 11 Jan 2016.

30. Peters FT, Hartung M, Herbold M, Schmitt G, Daldrup T, Mußhoff F. Anhang B zur Richtlinie der GTFCh zur Qualitätssicherung bei forensisch-toxikologischen Untersuchungen - Anforderungen an die Validierung von Analysenmethoden. Toxichem Krimtech. 2009;76:185-208. 